\title{
Article \\ Photoinduced Porcine Gelatin Cross-Linking by Homobi- and Homotrifunctional Tetrazoles
}

\author{
Luca Vaghi $^{1, *(\mathbb{D})}$, Mauro Monti ${ }^{1}$, Marcello Marelli ${ }^{2} \mathbb{D}$, Elisa Motto ${ }^{3}$, Antonio Papagni ${ }^{1, *}$ and Laura Cipolla ${ }^{3, *(\mathbb{D})}$ \\ 1 Dipartimento di Scienza dei Materiali, Università degli Studi di Milano-Bicocca, via R. Cozzi 55, \\ 20125 Milano, Italy; mauro.monti@unimib.it \\ 2 Istituto di Scienze e Tecnologie Chimiche "Giulio Natta”, CNR-SCITEC, Sede Fantoli, via Fantoli 16/15, \\ 20138 Milano, Italy; marcello.marelli@scitec.cnr.it \\ 3 Dipartimento di Biotecnologie e Bioscienze, Università degli Studi di Milano-Bicocca, Piazza della Scienza 2, \\ 20126 Milano, Italy; e.motto2@campus.unimib.it \\ * Correspondence: luca.vaghi@unimib.it (L.V.); Antonio.papagni@unimib.it (A.P.); \\ laura.cipolla@unimib.it (L.C.)
}

Citation: Vaghi, L.; Monti, M.;

Marelli, M.; Motto, E.; Papagni, A.; Cipolla, L. Photoinduced Porcine

Gelatin Cross-Linking by Homobiand Homotrifunctional Tetrazoles. Gels 2021, 7, 124. https://doi.org/ $10.3390 /$ gels7030124

Academic Editor: Vijay

Kumar Thakur

Received: 17 July 2021

Accepted: 16 August 2021

Published: 20 August 2021

Publisher's Note: MDPI stays neutral with regard to jurisdictional claims in published maps and institutional affiliations.

Copyright: (c) 2021 by the authors. Licensee MDPI, Basel, Switzerland. This article is an open access article distributed under the terms and conditions of the Creative Commons Attribution (CC BY) license (https:/ / creativecommons.org/licenses/by/ $4.0 /)$.

\begin{abstract}
Gelatin is a costless polypeptide material of natural origin, able to form hydrogels that are potentially useful in biomaterial scaffold design for drug delivery, cell cultures, and tissue engineering. However, gelatin hydrogels are unstable at physiological conditions, losing their features only after a few minutes at $37^{\circ} \mathrm{C}$. Accordingly, treatments to address this issue are of great interest. In the present work, we propose for the first time the use of bi- and trifunctional tetrazoles, most of them unknown to date, for photoinduced gelatin cross-linking towards the production of physiologically stable hydrogels. Indeed, after UV-B irradiation, aryl tetrazoles generate a nitrilimine intermediate that is reactive towards different functionalities, some of them constitutively present in the amino acid side chains of gelatin. The efficacy of the treatment strictly depends on the structure of the cross-linking agent used, and substantial improved stability was observed by switching from bifunctional to trifunctional cross-linkers.
\end{abstract}

Keywords: gelatin; hydrogel; photochemistry; tetrazoles; nitrilimine; chemical cross-linking; natural polymers

\section{Introduction}

Proteins are valuable polymers, serving as biomaterials in applications that revolutionized regenerative medicine, tissue regeneration [1,2], and drug delivery [3] in recent decades. Proteins derived from extracellular matrices (ECM, i.e., collagen, fibronectin, laminin [4,5]) offer several advantages over non-natural materials, since they support cell growth and tissue regeneration, reduce undesired side effects, and are biodegradable and biocompatible. However, the main limiting factor to their use is their availability, which impacts costs, and effective substitutes for ECM proteins are thus highly desirable. In this framework, gelatin is a widespread natural polymer used for the design of innovative biomaterials as an ECM protein substitute [6] and as a drug delivery vehicle [7], already used in well-established applications in the pharmaceutical, cosmetic, and food industries [8]. Gelatin is obtained from collagen by chemical or enzymatic hydrolysis, or heat denaturation, and subsequently manufactured with different advanced techniques such as electrospinning, 3D-printing, solvent casting, rapid prototyping, and bioprinting in different scaffolds with the desired morphology, topography, mechanical, and biological properties $[9,10]$. Gelatin offers the advantage of being readily and widely available, water soluble compared to other ECM proteins, and suitable for cell attachment in regenerative medicine applications. One disadvantage of gelatin in the fabrication of biomaterials is its poor mechanical strength [11-15], which may be improved by cross-linking. Cross-linking can be achieved either by chemical, enzymatic, or physical methods [16-19]. Chemical 
cross-linking offers advantages over physical methods, affording stable linkages and reproducibility. To achieve chemical cross-linking, either amino acid side chains $[20,21]$ or additional functional groups [22] suitably grafted to the protein can be employed. Regioselective and bioorthogonal chemistries can be used in order to fine-tune cross-linking and, by extension, the final properties of the biomaterial [23]. Bioorthogonal reactions rely on introduction into the polymers of functional groups different from those found in amino acid side chains, able to chemoselectively react in mild conditions with high yields. Among them, the so-called click chemistry [24-27], based, for example, on Huisgen-type cycloaddition [28], Staudinger reaction [29,30], Diels-Alder [31-33], thiol-ene addition [34,35], and carbonyl/oxime-hydrazone chemistry $[36,37]$, has been proposed over recent years. The main drawback of bioorthogonal reactions arises from the need for a two-step process, involving first the introduction of orthogonal functional groups, either by chemical or enzymatic reactions [38] or protein engineering [39] approaches. On the other hand, reactions based on the direct cross-linking of amino acid side chains may suffer from the release of (toxic) by-products, which are difficult to be eliminate. Several examples of gelatin cross-linking, both by click chemistry [40-44] and direct cross-linking based on intrinsic amino acid reactivity, were proposed. Direct cross-linking can be obtained by homo- or ethero-difunctional cross-linking agents of natural origin, such as citric acid [45], and genipin [46], or non-natural ones, including bisvinyl sulfonemethyl (BVSM) [47], 1,4-butanediol diglycidyl ether (BDDGE) [16], triazolinediones [48], and the widely-used glutaraldehyde $[49,50]$.

Despite great advances in recent years, the search for additional chemistries that can be applied to amino acid side chain reactivity in order to achieve chemoselectivity, a one-step reaction, and no by-products, is still on-going.

Tetrazoles were recently used as photoactivable precursors for the reaction towards biological nucleophiles [51-53]. Upon UV irradiation, the tetrazole moiety release a nitrogen molecule to produce a highly reactive nitrilimine intermediate, able to react with a plethora of functional groups (Scheme 1) [54-56].

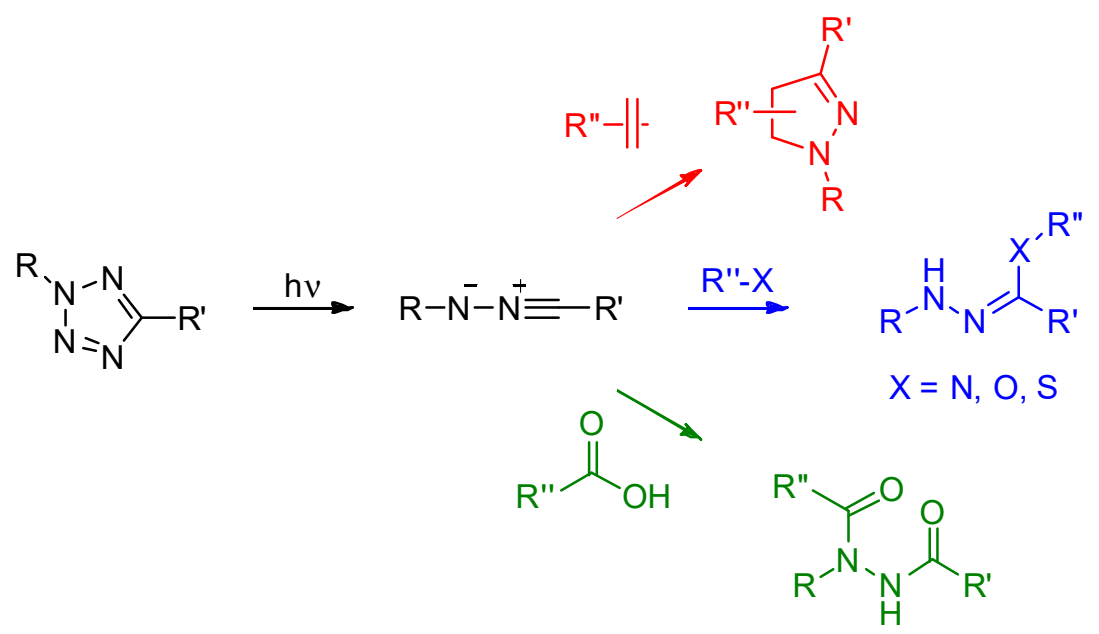

Scheme 1. Photoinduced nitrilimine generation and reactivity towards functional groups.

Even if it is possible to direct the reactivity of nitrilimines to the desired functionality by varying the reaction conditions [52], complete selectivity is almost unattainable, and unpredictable results were observed with complex biological substrates [53]. This behavior could be detrimental to achieving a site-selective functionalization or bioconjugation. However, it may be ideal as an effective cross-linking strategy to achieve improvements in the macroscopic characteristics of biological materials, such as gelatin. Intrigued by this possibility and exploiting our expertise in the synthesis of heterocyclic compounds [57-60], we prepared a set of bi- and trifunctional tetrazoles and applied them for the first time in the photoinduced cross-linking of porcine skin gelatin. 


\section{Results and Discussion}

\subsection{Synthesis of Cross-Linking Agents}

Four homo-bifunctional and one homo-trifunctional tetrazoles were synthesized, four of them unknown to date, to be used in the photoinduced cross-linking of gelatin (Scheme 2).
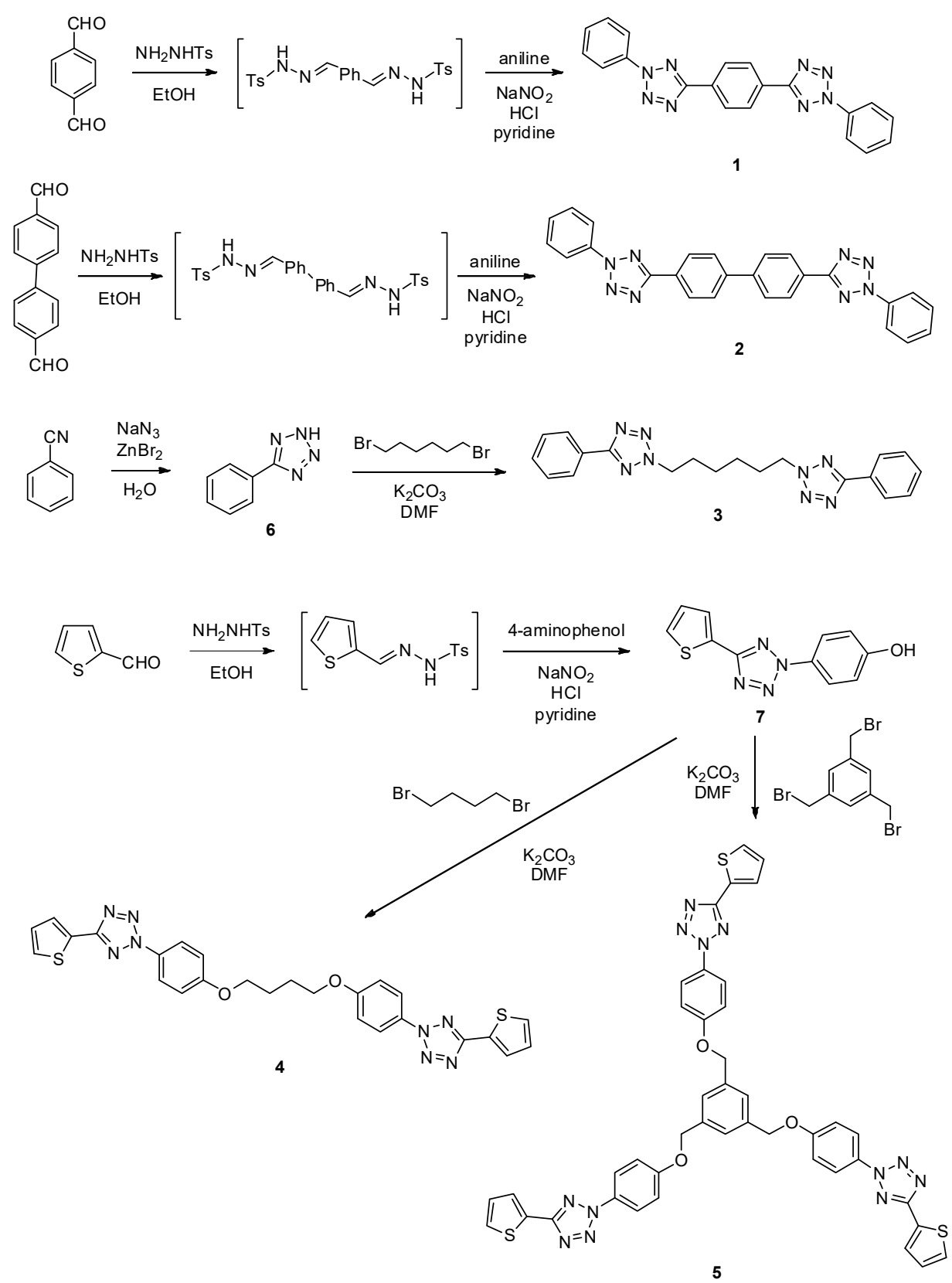

Scheme 2. Synthesis of the cross-linking agents 1-5 used in this study.

Cross-linking agent 1 was previously reported [61,62], however for its preparation in this study, a different synthetic strategy was used, involving the treatment of terephthalaldehyde bistosylhydrazone with diazonium aniline salt [63]. By the same methodology, using 4,4'-diformylbiphenyl instead of terephthalaldehyde tetrazole, 2 was easily obtained. The preparation of 3,4 , and 5 involved the synthesis of the tetrazole moiety, then, via alkylation with the suitable di- and tri-bromo derivatives, the desired compound was obtained; i.e., 5-phenyl-2H-tetrazole 6 [64] was treated with 1,6-dibromohexane in the presence of $\mathrm{K}_{2} \mathrm{CO}_{3}$ in the case of 3, while 4-(5-(thiophen-2-yl)-2H-tetrazol-2-yl)phenol 7, achieved by treatment of 2-thiophenecarboxyaldehyde tosylhydrazone with the diazonium salt of 
4-aminophenol, was reacted with 1,4-dibromobutane and 1,3,5-tris(bromomethyl)benzene in presence of $\mathrm{K}_{2} \mathrm{CO}_{3}$ to afford 4 and 5, respectively. Detailed synthetic procedures are reported in the Supplementary Materials.

\subsection{PhotoInduced Gelatin Cross-Linking}

The amino acid composition of porcine gelatin [65] shows the significant presence of glutamic acid $(7.2 \mathrm{~mol} \%)$ and aspartic acid $(4.7 \mathrm{~mol} \%)$ residues, whose carboxylic acid side chains could be targeted by photoactivated tetrazoles [51,52], as well as traces of hystidine $(0.6 \mathrm{~mol} \%)$, terminals $\mathrm{COOH}$ and $\mathrm{NH}_{2}$, and other possible reactive peptide side chain sites among the polypeptide network of gelatin. The perfect solubilization of both gelatin and selected cross-linking agent in the reaction media is desirable, in order to allow the cross-linker to reach the reactive sites and achieve reproducible cross-linking results. Dimethyl sulfoxide (DMSO) was selected as the media for photoinduced cross-linking procedures, as it is able to solubilize both gelatin (up to $12 \mathrm{mg} / \mathrm{mL}$ ) and cross-linkers 1-5. Thus, a set of experiments at increasing linker:gelatin ratios was planned, i.e., $100 \mathrm{mg}$ of dry gelatin in the presence of $1,2,5$, and $10 \mu \mathrm{mol}$ of cross linker (the use of $20 \mu \mathrm{mol}$ results in a heterogeneous mixture for almost every compound). Before the UV irradiation of gelatin-tetrazole homogeneous DMSO solution, it is important to remove oxygen from the reaction environment, together with a reduction in the UV-C component, in order to avoid UV-related oxidative damage to the polypeptide network [66-68]. Therefore, the solutions were bubbled with flowing nitrogen for 15 min before irradiation and maintained under an inert atmosphere during the photoinduced reaction. Standard borosilicate glassware was used, as this material transmit over $90 \%$ of UV light with wavelengths greater than $300 \mathrm{~nm}$, while partially filtering the undesirable UV-C [69], and at the same time being reliable in the photoactivation of tetrazoles [55]. No absorption interference was expected from gelatin (as it is totally transparent to wavelengths $>240 \mathrm{~nm}$ [70]) or DMSO (as it absorbs no UV-B wavelengths, with a cutoff around $260 \mathrm{~nm}$ ). The photoactivation of tetrazole is reported to be highly effective. Kinetic studies of the photoinduced nucleophilic attack demonstrated that addition between tetrazoles and $\mathrm{COOH}$ groups could be completed in less than $10 \mathrm{~min}$, unless a strong electron-withdrawing group is present on either the $\mathrm{C}$ or $\mathrm{N}$ moiety of 2,5-tetrazoles [51,56], which is not the case for compounds $\mathbf{1 - 5}$. The solutions, under vigorous stirring, were then irradiated with two coupled low-pressure mercury UV-B lamps with a peak at $310 \mathrm{~nm}$, for $10 \mathrm{~min}$.

The workup of the reaction mixture is fundamental to remove any trace of unreacted cross-linker, byproducts, and organic solvents from the hydrogels. Cross-linked gelatin precipitation from reaction media was the method of choice. The solvent used for the precipitation of the gelatin from the reaction medium (DMSO) must afford a satisfactory quantity of recovered gel without changing its properties, be miscible with DMSO for the precipitation and with $\mathrm{H}_{2} \mathrm{O}$ to be subsequently removed, and able to solubilize unreacted cross-linker and possible byproducts. Thus, methanol, ethanol, 2-propanol, and tetrahydrofuran (THF) were tested. All are effective for the precipitation of the hydrogels (2-propanol afforded lower yield); however, alcohols were unable to dissolve tetrazoles 1-5, and consequently THF was selected for the workup step. Therefore, the treated gelatins were precipitated from the reaction solutions by 1:1 $v / v$ addition of THF, and the obtained hydrogels were subsequently washed first with THF to remove unreacted crosslinkers and byproducts, then washed multiple times with $\mathrm{H}_{2} \mathrm{O}$, and finally kept in $\mathrm{H}_{2} \mathrm{O}$ overnight to remove any traces of DMSO and THF by diffusion. The recovered hydrogels were finally freeze-dried for the subsequent experiments.

\subsection{Thermal Stability of Prepared Hydrogels}

One of the major disadvantages of gelatin-based hydrogels is the poor resistance to physiological conditions (i.e., at $37{ }^{\circ} \mathrm{C}$ they almost immediately dissolve). Thus, the prepared dry gelatin specimens were rehydrated with PBS buffer $(\mathrm{pH}=7.4)$ and sealed and placed in a $37^{\circ} \mathrm{C}$ thermostated chamber to test their thermal stability in comparison to 
blank gelatin treated in the same way, but without the presence of any cross-linker. The time evolution of hydrogels is depicted in Figure 1.

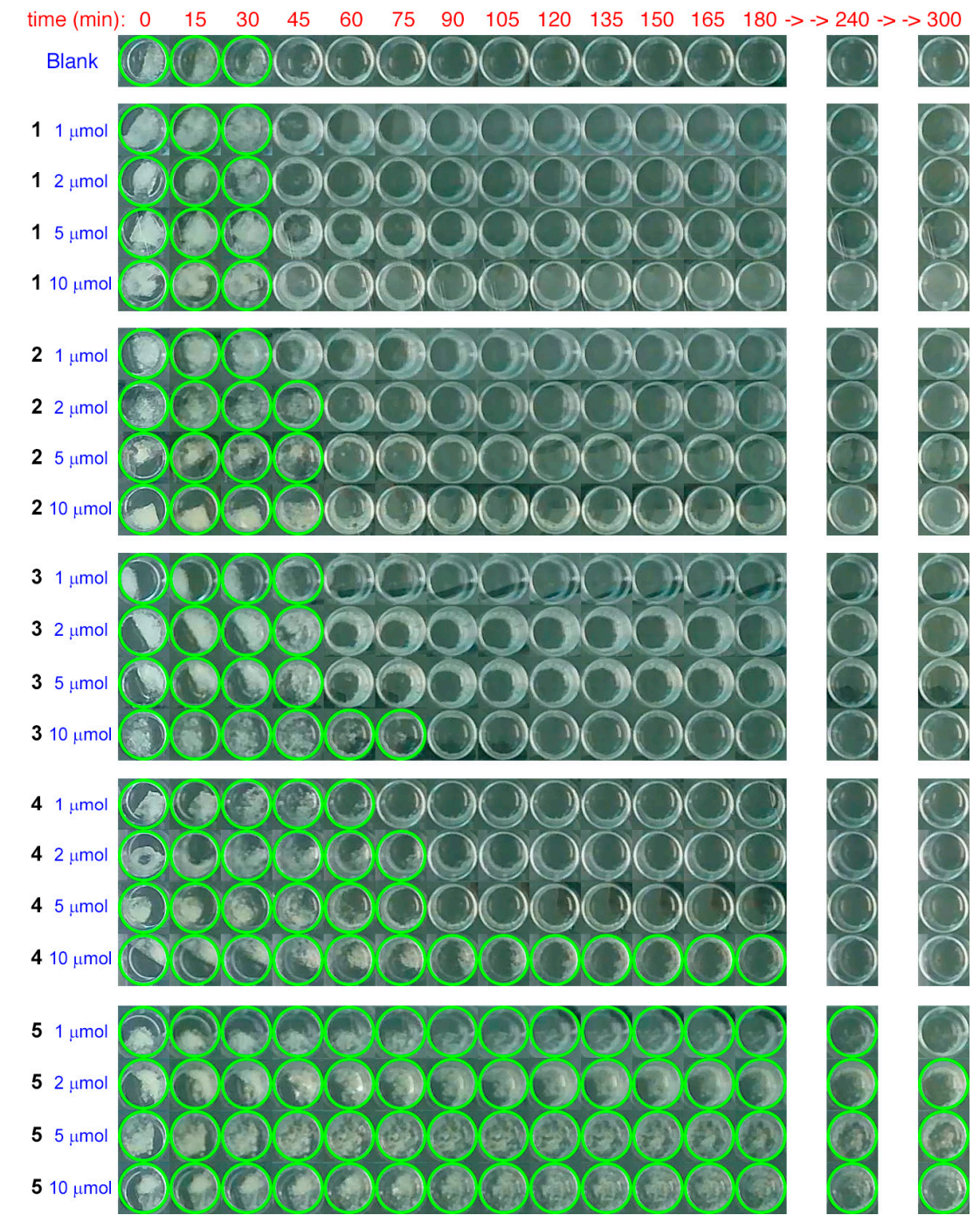

Figure 1. Time evolution of prepared hydrogels at $37^{\circ} \mathrm{C}$. Images of the sealed wells were caught every $15 \mathrm{~min}$. When hydrogel consistence is maintained the well is circled in green (original video frames are presented in the Supplementary Materials).

Blank gelatin resists $30 \mathrm{~min}$ in these conditions before complete dissolution. No stability improvements were observed for all samples treated with $\mathbf{1}(1,2,5$, and $10 \mu \mathrm{mol})$ and 2 at the lowest amount $(1 \mu \mathrm{mol})$, while a slight $15 \mathrm{~min}$ increase in thermal resistance was obtained using 2 at higher amounts $(2,5$, and $10 \mu \mathrm{mol})$ and $3(1,2$, and $5 \mu \mathrm{mol})$. The first significant differences were noted with gelatin treated with 3 at $10 \mu \mathrm{mol}$, which remained stable for $75 \mathrm{~min}$, and with cross-linker 4 that afforded 60, 75, and $180 \mathrm{~min}$ of thermal resistance at increasing amounts of $1,2 / 5$, and $10 \mu \mathrm{mol}$, respectively. Switching to trifunctional cross-linker 5, a substantial increment in thermal stability was observed, even at the lowest amount tested: at a $1 \mu \mathrm{mol} / 100 \mathrm{mg}$ gelatin ratio, the specimen maintained hydrogel consistence up to $240 \mathrm{~min}$, while at higher cross-linker amounts $(2,5$, and $10 \mu \mathrm{mol})$, no dissolution was observed over $24 \mathrm{~h}$.

These results may be explained by three main issues considering cross-linking agents 1-5, namely their structure, photoactivation, and reactivity.

Concerning the structure, there are two points to consider: first, the distance between the two functional groups reacting with amino acid side chains should be high enough 
for cross-linking (usually referred to as cross-linker length). Among the cross-linkers 1-5, compound 1 has the shortest length, thus possibly explaining its poor performance in the cross-linking reaction. Second, conformational flexibility may improve the ability of linkers to catch reactive functional groups in the complex, tridimensional structure of gelatin: in this respect, $\mathbf{1}$ and $\mathbf{2}$ have limited conformational freedom compared to 3, 4, and $\mathbf{5}$.

As anticipated, photoactivation of 2,5-tetrazoles is reported to be highly effective [51,56], and $10 \mathrm{~min}$ of UV irradiation with a power $(30 \mathrm{~W})$ five time greater than that used in the literature $(6 \mathrm{~W})$ was assumed as a sufficient time for gelatin cross-linking to occur. In order to better characterize the reactivity of the system, $\lambda_{\max }$ of $\mathbf{1 - 5}$ was determined to check if they fit the settled irradiation window: 1, 2, 4, and 5 displayed the maximum absorbance around $300 \mathrm{~nm}$, with a perfect fit of 2 at $312 \mathrm{~nm}$, while the absorption of 3, where the aryl substituent on tetrazole nitrogen is replaced by an alkyl chain, was at more energetic wavelengths with a $\lambda_{\max }$ below $265 \mathrm{~nm}$. In this case, a limited portion of the irradiating setup was useful for tetrazole activation.

A combination of the above-mentioned considerations resulted in a better performance of 4 and $\mathbf{5}$ in respect to 1,2 , and $\mathbf{3}$. However, a crucial point to be considered is the competing reaction of nitrilimine intermediates towards gelatin $\mathrm{COOH}$ groups and the decomposition pathways. The reaction of photoactivated 2,5-diaryltetrazoles in the presence of a large excess of unhindered carboxylic acids affords $N^{\prime}$-acyl- $N^{\prime}$-phenylbenzohydrazides in up to $80 \%$ yields $[52,55]$. However, increased steric hindrance near the $\mathrm{COOH}$ functionality and/or lowered excess of the carboxylic acid cause a sensible drop in yield. Therefore, the application of this chemistry to gelatin, whose $\mathrm{COOH}$ functionalities may be hindered by the complex polypeptide structure and are not present in large excess in respect to the cross-linkers, may be much less effective than expected. Moreover, a cross-link requires that both the reactive moieties of a bifunctional reagent react with the target functionalities of the polymeric substrate. Accordingly, emerged the great advantage of trifunctional cross-linker 5 compared to bifunctional 1-4: when the first nitrilimine links to gelatin, 5 has two reactive sites for cross-linking, significantly increasing the chances of success.

Due to their poor to null thermal stability increment, specimens obtained by treatment of gelatin with compounds 1, 2, and $\mathbf{3}$ were not investigated further, while further characterization of specimens treated with 4 and 5 was performed.

\subsection{Characterization of Gelatin Treated with 4 and $\mathbf{5}$}

\subsubsection{Scanning Electron Microscopy Micrographs}

Low-vacuum scanning electron microscopy (SEM) was used to investigate the morphological structure of dry specimens after treatment with 4 and 5 at $10 \mu \mathrm{mol}$ (Figure 2). Changes in the morphology of treated samples with respect to the reference blank were observed. In detail, the gelatin treated with cross-linkers $\mathbf{4}$ and $\mathbf{5}$ showed an increase in the apparent porosity, with a more open texture, the formation of a structured network, and a less solid appearance. These effects are more marked with cross-linker 5.
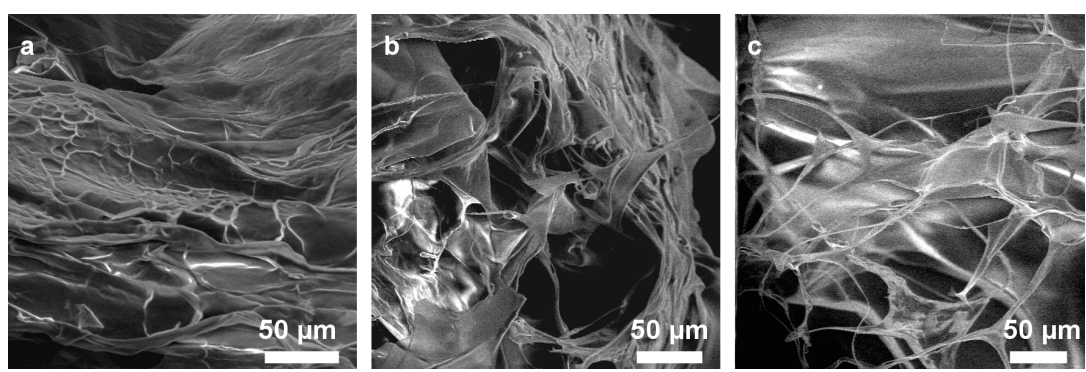

Figure 2. Representative SEM micrograph of dry gelatin samples: (a) pristine gelatin; (b) gelatin treated with $410 \mu \mathrm{mol}$; (c) gelatin treated with $510 \mu \mathrm{mol}$. 


\subsubsection{Swelling Properties}

Gelatin treated with cross-linkers 4 and $\mathbf{5}$ was tested for its swelling behavior in water by gravimetric analysis. The swelling properties of gel are usually dependent upon several factors, including the pore size of the network, non-covalent interactions among the network (polymer chains and treating agents) and the solvent, and the chains' mobility during the swelling process. The swelling degree (SD) and the equilibrium water content (EWC) for gels treated with $\mathbf{4}$ and $\mathbf{5}$ are reported in Figure 3. All of the hydrogel samples were prepared starting from the same quantity of freeze-dried specimens $(50 \mathrm{mg})$.

a)

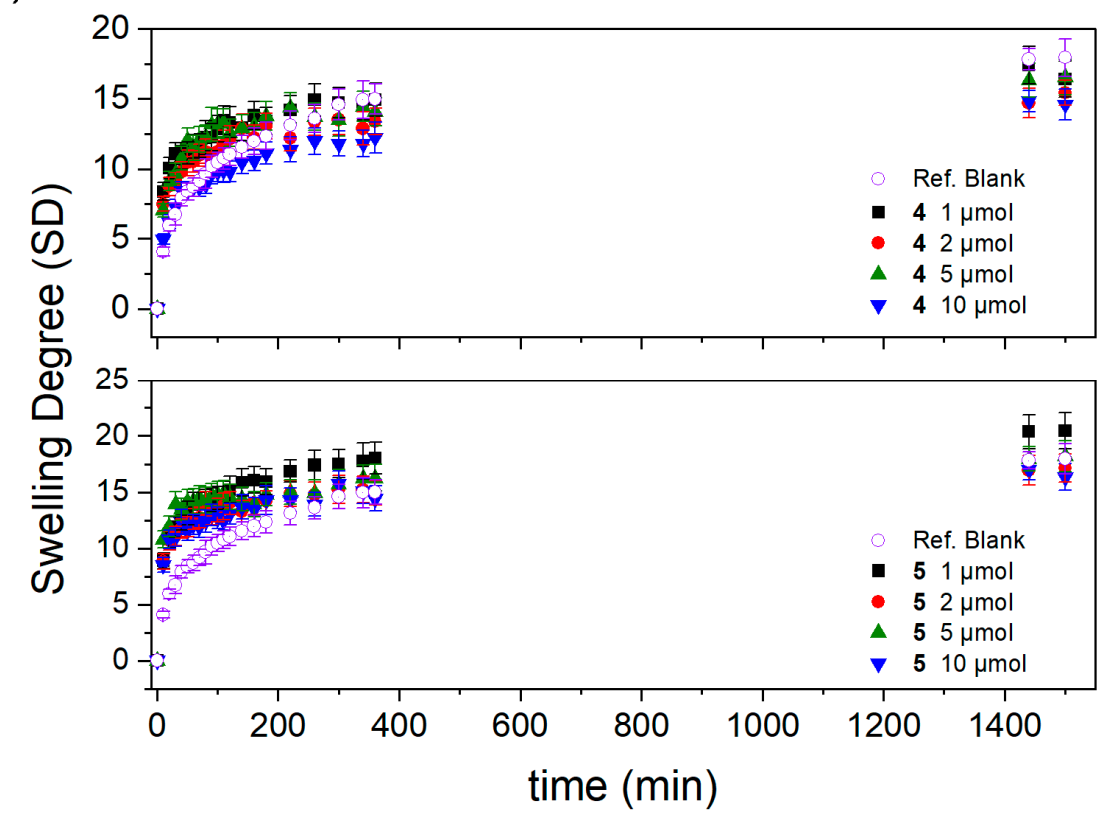

b)

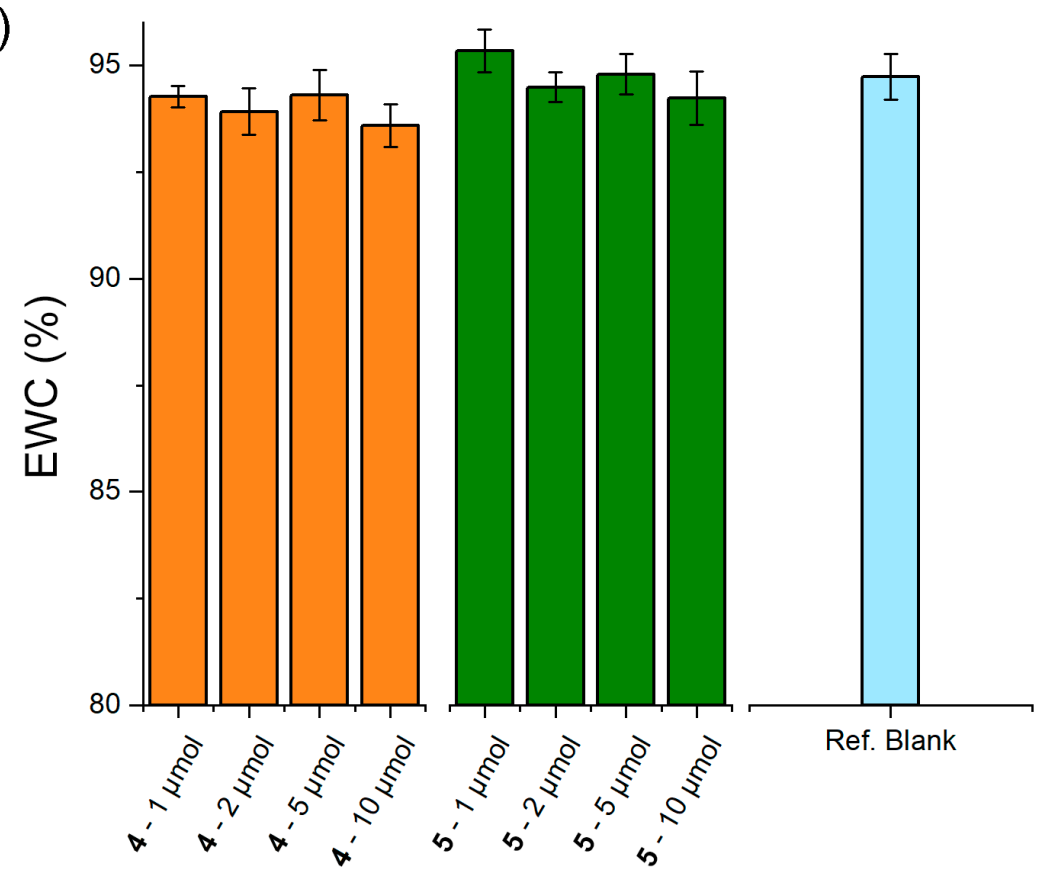

Figure 3. (a) Swelling behavior of gelatins treated with 4 and 5 at different concentrations in distilled $\mathrm{H}_{2} \mathrm{O}$, compared to untreated gelatin (blank); (b) water content of hydrogels at equilibrium.

The swelling behavior of samples treated with 4 is similar to untreated gelatin: a small increase in water absorption kinetic is observed for 1,2, and $5 \mu \mathrm{mol}$, but not for $10 \mu \mathrm{mol}$. 
This behavior is much more pronounced in all the samples treated with 5, with the first part of the SD curve noticeably higher than that of untreated gelatin. These observations are in accordance with the increased porosity of the tridimensional structure observed in the SEM micrographs. Equilibrium water content is a bit lower for samples treated with 4 , but in general, minimal differences are noticed.

\subsubsection{ATR-FTIR and ${ }^{1} \mathrm{H}$ NMR Analyses}

The ATR-FTIR spectra of gelatin treated with $\mathbf{4}$ and $\mathbf{5}$ are reported in Figure 4. No significant differences can be detected at any concentration of tetrazoles in respect to untreated gelatin.
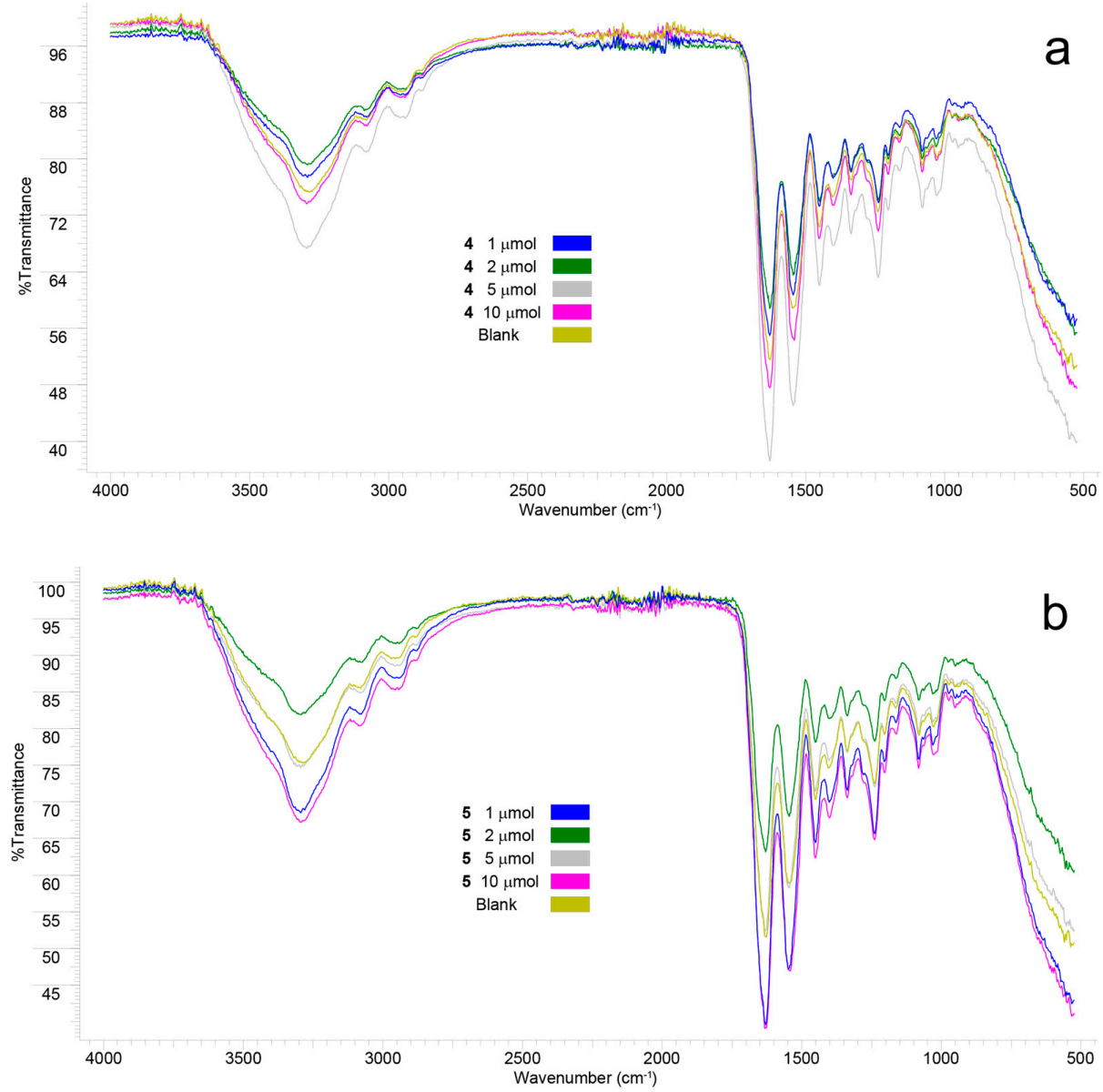

Figure 4. ATR-FTIR spectra of dry gelatins treated with 4 (a) and $5(\mathbf{b})$.

Similarly, changes were almost never detected by ${ }^{1} \mathrm{H}$ NMR analysis in the $\mathrm{D}_{2} \mathrm{O}$ of prepared specimens, which revealed the typical signal patterns of gelatin [71]. However, in samples treated with high concentrations of cross-linker 5, the presence of a group of small signals was observed near that of gelatin's tyrosine and phenylalanine resonances, attributable to the thiophene system of $\mathbf{5}$ (Figure 5a). 


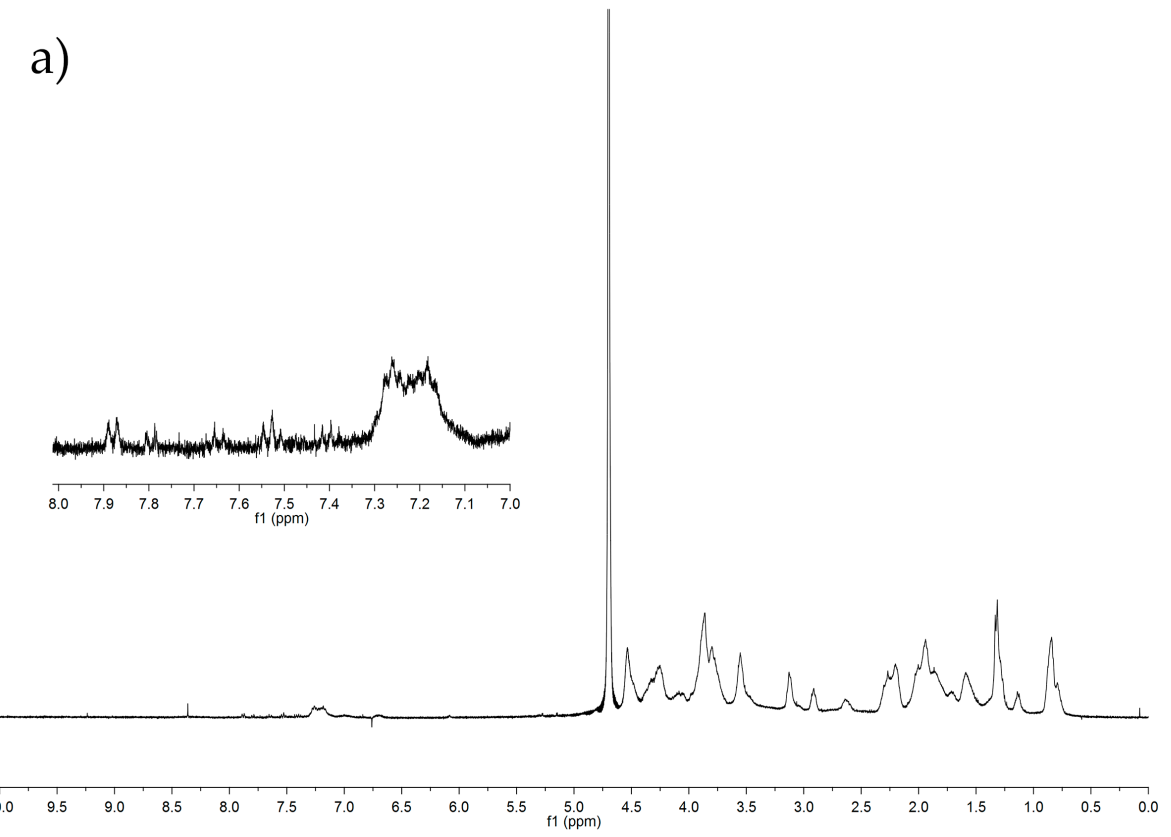

b)

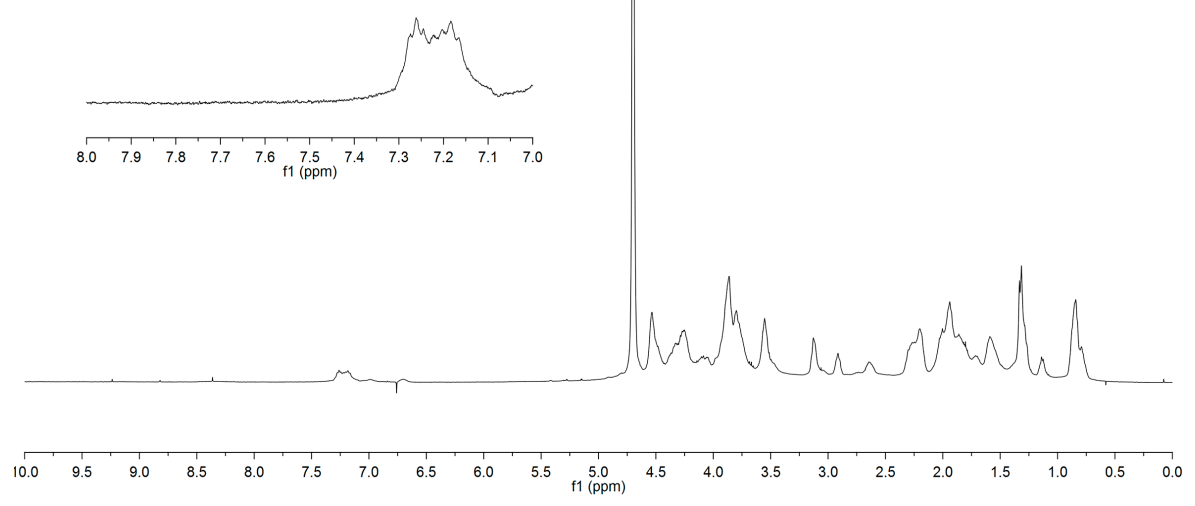

Figure 5. ${ }^{1} \mathrm{H}$ NMR $\left(400 \mathrm{MHz}, \mathrm{D}_{2} \mathrm{O}\right)$ of gelatin treated with 5, $5 \mu \mathrm{mol}$ (a) compared to untreated gelatin $(\mathbf{b})$.

\section{Conclusions}

In summary, for the first time, the photoinduced gelatin cross-linking with homobiand trifunctional tetrazoles via nitrilimine intermediates was proposed. Even if this chemistry has proven to be less effective than expected, which was also confirmed by the low degree of functionalization observed in the spectroscopic investigations, a significant increase in the thermal stability of gelatin hydrogels was achieved by using compounds 4 and especially 5 . The increased porosity and faster water absorption of treated samples deviate from the standard behavior of cross-linked biological matrices, which are normally less porous and less prone to water absorption compared to untreated starting materials. This study is of great importance for planning future applications of polyfunctional tetrazoles in photoinduced cross-linking of biological polymers, showing the necessity of planning the synthesis of cross-linkers endowed with multiple tetrazole photoactivable units. 


\section{Materials and Methods}

\subsection{General}

All reagents and solvents were purchased from commercial sources (Merck Life Science S.r.l., Milan, Italy; Fluorochem Ltd., Hadfield, UK; and TCI Europe N.V., Zwijndrecht, Belgium) and used without further purification. Gelatin from porcine skin-Type A was used for the hydrogel preparation (Merk, catalog no. G2500). NMR spectra were recorded with a Bruker AVANCE III HD $400 \mathrm{MHz}$ spectrometer (Bruker corp., Billerica, MA, USA). Two low-pressure mercury 15 W F15T8 UV-B lamps were simultaneously used for UV irradiation. The IR spectra were recorded with a Perkin Elmer Spectrum 100 FT-IR spectrometer equipped with a universal ATR sampling accessory (PerkinElmer Inc., Waltham, MA, USA). The scanning electron microscopy (SEM) analysis was performed with a Philips XL30 ESEM (FEI, Hillsboro, OR, USA). The gelatin was freeze-dried by a Christ alpha 1-2 freeze dryer (Christ, Osterode am Harz, Germany) at a temperature of $-55^{\circ} \mathrm{C}$ and at a pressure of $0.2-0.4 \mathrm{mBar}$. The UV $\lambda_{\max }$ was determined with a PerkinElmer Lambda 900 spectrophotometer (PerkinElmer Inc., Waltham, MA, USA). The melting points were measured with a Stanford Research Systems Optimelt apparatus (SRS, Sunnyvale, CA, USA).

\subsection{Synthesis of Cross-Linking Agents}

The synthetic procedures, complete characterizations, and ${ }^{1} \mathrm{H} \mathrm{NMR},{ }^{13} \mathrm{C} N \mathrm{NR}$, and ATR-FTIR spectra of $\mathbf{1}, \mathbf{2}, \mathbf{3}, \mathbf{4}$, and $\mathbf{5}$ are reported in the Supplementary Materials.

\subsection{Gelatin Cross-Linking}

In a borosilicate flask (UV absorption below $300 \mathrm{~nm}$ ), $100 \mathrm{mg}$ of gelatin in $8 \mathrm{~mL}$ of DMSO were heated at $37^{\circ} \mathrm{C}$ under magnetic stirring until complete dissolution (at least $8 \mathrm{~h}$ ). After cooling to r.t., the cross-linking agent $(1,2,5$, and $10 \mu \mathrm{mol} / 100 \mathrm{mg}$ of gelatin) was added and the mixture and stirred until homogeneity was achieved. The solution was then deoxygenated by $\mathrm{N}_{2}$ bubbling and irradiated at $310 \mathrm{~nm}(2 \times 15 \mathrm{watt}$, at $20 \mathrm{~cm})$ for $10 \mathrm{~min}$, under vigorous stirring and an $\mathrm{N}_{2}$ atmosphere. THF $(8 \mathrm{~mL})$ was added to the solution, and the resulting suspension was centrifuged at $7500 \mathrm{rpm}$ for $30 \mathrm{~min}$ before the supernatant was carefully removed. THF $(8 \mathrm{~mL})$ was added to the residue, and the mixture was vortexed ( $3000 \mathrm{rpm}$ ) for $2 \mathrm{~min}$ and centrifuged at $7500 \mathrm{rpm}$ for $30 \mathrm{~min}$. After careful removal of the supernatant, demineralized $\mathrm{H}_{2} \mathrm{O}(10 \mathrm{~mL})$ was added, the suspension was vortexed (3000 rpm) for $2 \mathrm{~min}$, centrifuged at $7500 \mathrm{rpm}$ for $30 \mathrm{~min}$, and the supernatant was carefully removed; this step was repeated twice. The obtained hydrogel was soaked in demineralized $\mathrm{H}_{2} \mathrm{O}$ overnight, recovered, and freeze-dried, yielding a weight of 60 to $80 \%$ that of the starting gelatin.

\subsection{Thermal Stability}

Freeze-dried, cross-linked gelatin specimens (ca $50 \mathrm{mg}$ ) and 4 control specimens worked in the same way as the treated samples were placed in tagged wells of a 24 multiwell plate, hydrated with PBS ( $4 \mathrm{~mL}, \mathrm{pH}=7.4$, physiological conditions), and kept sealed at $37^{\circ} \mathrm{C}$. The specimens were filmed with a $720 \mathrm{p}$ digital camera (video frames are presented in the Supplementary Materials) and periodically inspected.

\subsection{SEM Iimaging}

Scanning electron microscopy (SEM) analysis was performed working at $12 \mathrm{kV}$ accelerating voltage and in low vacuum mode ( 0.8 Torr). Samples were dried, cut, fixed with conductive carbon tape to standard SEM stubs, and directly analyzed. Working in low vacuum conditions, no conductive coatings were applied, in order to preserve the original structure. Samples showed good stability under electron beam illumination at the operating conditions. 


\subsection{Swelling Studies}

Dynamic swelling measurements were made by gravimetric measurements. Freezedried gelatin specimens (ca $50 \mathrm{mg}$ ) were soaked in distilled water at r.t. The swollen gels were periodically removed from water, blotted with filter paper, weighed on an analytical balance, and returned to the swelling medium until the equilibrium was reached.

The swelling degree (SD) was calculated from the following equation and reported as a function of time:

$$
\text { Swelling degree }\left(\mathrm{SD}, \mathrm{g} \cdot \mathrm{g}^{-1}\right)=\left(\mathrm{W}_{\mathrm{t}}-\mathrm{W}_{0}\right) \cdot \mathrm{W}_{0}{ }^{-1}
$$

where $\mathrm{W}_{\mathrm{t}}$ is the weight of swelling hydrogel at different times and $\mathrm{W}_{0}$ is the dry weight of the gel.

The equilibrium water content (EWC), was calculated from the following equation:

$$
\operatorname{EWC}(\%)=\left(\mathrm{W}_{\mathrm{e}}-\mathrm{W}_{0}\right) \cdot \mathrm{We}^{-1} \cdot 100
$$

where $\mathrm{W}_{\mathrm{e}}$ is the swelling weight of the sample at equilibrium and $\mathrm{W}_{0}$ is the dry weight of the gel.

Supplementary Materials: The following are available online at https:/ /www.mdpi.com/article/10 .3390 /gels7030124/s1: procedures for the synthesis of cross-linkers $1-5 ;{ }^{1} \mathrm{H} \mathrm{NMR},{ }^{13} \mathrm{C}$ NMR, and ATR-FTIR spectra of synthesized compounds; and video frames of the thermal stability test at $37^{\circ} \mathrm{C}$.

Author Contributions: Conceptualization, L.V., A.P. and L.C.; methodology, L.V.; formal analysis, L.V., E.M., M.M. (Marcello Marelli), and M.M. (Mauro Monti); investigation, L.V., E.M., M.M. (Marcello Marelli), and M.M. (Mauro Monti); writing—original draft preparation, L.V.; writingreview and editing, A.P. and L.C.; visualization, L.V., M.M. (Marcello Marelli) and M.M. (Mauro Monti); supervision, A.P. and L.C. All authors have read and agreed to the published version of the manuscript.

Funding: This research received no external funding.

Acknowledgments: We would like to thank Giorgio Patriarca for the NMR analysis.

Conflicts of Interest: The authors declare no conflict of interest.

\section{References}

1. Echave, M.C.; Saenz del Burgo, L.; Pedraz, J.L.; Orive, G. Gelatin as Biomaterial for Tissue Engineering. Curr. Pharm. Des. 2017, 23, 3567-3584. [CrossRef] [PubMed]

2. Aldana, A.A.; Abraham, G.A. Current Advances in Electrospun Gelatin-Based Scaffolds for Tissue Engineering Applications. Int. J. Pharm. 2017, 523, 441-453. [CrossRef] [PubMed]

3. Foox, M.; Zilberman, M. Drug Delivery from Gelatin-Based Systems. Expert Opin. Drug Deliv. 2015, 12, 1547-1563. [CrossRef] [PubMed]

4. Goh, K.; Holmes, D. Collagenous Extracellular Matrix Biomaterials for Tissue Engineering: Lessons from the Common Sea Urchin Tissue. Int. J. Mol. Sci. 2017, 18, 901. [CrossRef]

5. Parenteau-Bareil, R.; Gauvin, R.; Berthod, F. Collagen-Based Biomaterials for Tissue Engineering Applications. Materials 2010, 3, 1863-1887. [CrossRef]

6. Bello, A.B.; Kim, D.; Kim, D.; Park, H.; Lee, S.-H. Engineering and Functionalization of Gelatin Biomaterials: From Cell Culture to Medical Applications. Tissue Eng. Part B Rev. 2020, 26, 164-180. [CrossRef]

7. Jaipan, P.; Nguyen, A.; Narayan, R.J. Gelatin-Based Hydrogels for Biomedical Applications. MRS Commun. 2017, 7, $416-426$. [CrossRef]

8. Nur Hanani, Z.A.; Roos, Y.H.; Kerry, J.P. Use and Application of Gelatin as Potential Biodegradable Packaging Materials for Food Products. Int. J. Biol. Macromol. 2014, 71, 94-102. [CrossRef]

9. Collins, M.N.; Ren, G.; Young, K.; Pina, S.; Reis, R.L.; Oliveira, J.M. Scaffold Fabrication Technologies and Structure/Function Properties in Bone Tissue Engineering. Adv. Funct. Mater. 2021, 31, 2010609. [CrossRef]

10. Thakur, S.; Govender, P.P.; Mamo, M.A.; Tamulevicius, S.; Thakur, V.K. Recent Progress in Gelatin Hydrogel Nanocomposites for Water Purification and Beyond. Vacuum 2017, 146, 396-408. [CrossRef]

11. Li, X.; Zhang, J.; Kawazoe, N.; Chen, G. Fabrication of Highly Crosslinked Gelatin Hydrogel and Its Influence on Chondrocyte Proliferation and Phenotype. Polymers 2017, 9, 309. [CrossRef] [PubMed] 
12. Dash, R.; Foston, M.; Ragauskas, A.J. Improving the Mechanical and Thermal Properties of Gelatin Hydrogels Cross-Linked by Cellulose Nanowhiskers. Carbohydr. Polym. 2013, 91, 638-645. [CrossRef] [PubMed]

13. Xing, Q.; Yates, K.; Vogt, C.; Qian, Z.; Frost, M.C.; Zhao, F. Increasing Mechanical Strength of Gelatin Hydrogels by Divalent Metal Ion Removal. Sci. Rep. 2014, 4, 4706. [CrossRef] [PubMed]

14. Clapacs, Z.; Neal, S.; Schuftan, D.; Tan, X.; Jiang, H.; Guo, J.; Rudra, J.; Huebsch, N. Biocompatible and Enzymatically De-gradable Gels for 3D Cellular Encapsulation under Extreme Compressive Strain. Gels 2021, 7, 101. [CrossRef]

15. Basara, G.; Ozcebe, S.G.; Ellis, B.W.; Zorlutuna, P. Tunable Human Myocardium Derived Decellularized Extracellular Matrix for 3D Bioprinting and Cardiac Tissue Engineering. Gels 2021, 7, 70. [CrossRef]

16. Oryan, A.; Kamali, A.; Moshiri, A.; Baharvand, H.; Daemi, H. Chemical crosslinking of biopolymeric scaffolds: Current knowledge and future directions of crosslinked engineered bone scaffolds. Int. J. Biol. Macromol. 2018, 107, 678-688. [CrossRef]

17. Sgambato, A.; Cipolla, L.; Russo, L. Bioresponsive Hydrogels: Chemical Strategies and Perspectives in Tissue Engineering. Gels 2016, 2, 28. [CrossRef] [PubMed]

18. Shankar, K.G.; Gostynska, N.; Montesi, M.; Panseri, S.; Sprio, S.; Kon, E.; Marcacci, M.; Tampieri, A.; Sandri, M. Investigation of Different Cross-Linking Approaches on 3D Gelatin Scaffolds for Tissue Engineering Application: A Comparative Analysis. Int. J. Biol. Macromol. 2017, 95, 1199-1209. [CrossRef]

19. Reddy, N.; Reddy, R.; Jiang, Q. Crosslinking biopolymers for biomedical applications. Trends Biotechnol. 2015, 33, 362-369. [CrossRef]

20. Baslé, E.; Joubert, N.; Pucheault, M. Protein Chemical Modification on Endogenous Amino Acids. Chem. Biol. 2010, 17, 213-227. [CrossRef]

21. Spicer, C.D.; Davis, B.G. Selective Chemical Protein Modification. Nat. Commun. 2014, 5, 4740. [CrossRef] [PubMed]

22. Sletten, E.M.; Bertozzi, C.R. Bioorthogonal Chemistry: Fishing for Selectivity in a Sea of Functionality. Angew. Chem. Int. Ed. 2009, 48, 6974-6998. [CrossRef] [PubMed]

23. Azagarsamy, M.A.; Anseth, K.S. Bioorthogonal Click Chemistry: An Indispensable Tool to Create Multifaceted Cell Culture Scaffolds. ACS Macro Lett. 2013, 2, 5-9. [CrossRef]

24. Lallana, E.; Fernandez-Trillo, F.; Sousa-Herves, A.; Riguera, R.; Fernandez-Megia, E. Click Chemistry with Polymers, Dendrimers, and Hydrogels for Drug Delivery. Pharm. Res. 2012, 29, 902-921. [CrossRef]

25. Jiang, Y.; Chen, J.; Deng, C.; Suuronen, E.J.; Zhong, Z. Click Hydrogels, Microgels and Nanogels: Emerging Platforms for Drug Delivery and Tissue Engineering. Biomaterials 2014, 35, 4969-4985. [CrossRef]

26. Jewett, J.C.; Bertozzi, C.R. Cu-Free Click Cycloaddition Reactions in Chemical Biology. Chem. Soc. Rev. 2010, 39, 1272-1279. [CrossRef]

27. Xu, L.; Kuan, S.L.; Weil, T. Contemporary Approaches for Site-Selective Dual Functionalization of Proteins. Angew. Chem. Int. Ed. 2021, 60, 13757-13777. [CrossRef]

28. Lutz, J.F.; Zarafshani, Z. Efficient Construction of Therapeutics, Bioconjugates, Biomaterials and Bioactive Surfaces Using Azide-Alkyne "Click" Chemistry. Adv. Drug Deliv. Rev. 2008, 60, 958-970. [CrossRef] [PubMed]

29. van Berkel, S.S.; van Eldijk, M.B.; van Hest, J.C.M. Staudinger Ligation as a Method for Bioconjugation. Angew. Chem. Int. Ed. 2011, 50, 8806-8827. [CrossRef] [PubMed]

30. Schilling, C.I.; Jung, N.; Biskup, M.; Schepers, U.; Bräse, S. Bioconjugation via Azide-Staudinger Ligation: An Overview. Chem. Soc. Rev. 2011, 40, 4840-4871. [CrossRef] [PubMed]

31. Pozsgay, V.; Vieira, N.E.; Yergey, A. A Method for Bioconjugation of Carbohydrates Using Diels-Alder Cycloaddition. Org. Lett. 2002, 4, 3191-3194. [CrossRef] [PubMed]

32. Willems, L.I.; Verdoes, M.; Florea, B.I.; van der Marel, G.A.; Overkleeft, H.S. Two-Step Labeling of Endogenous Enzymatic Activities by Diels-Alder Ligation. Chembiochem 2010, 11, 1769-1781. [CrossRef] [PubMed]

33. Gregoritza, M.; Brandl, F.P. The Diels-Alder Reaction: A Powerful Tool for the Design of Drug Delivery Systems and Biomaterials. Eur. J. Pharm. Biopharm. 2015, 97, 438-453. [CrossRef] [PubMed]

34. Dondoni, A. The Emergence of Thiol-Ene Coupling as a Click Process for Materials and Bioorganic Chemistry. Angew. Chem. Int. Ed. 2008, 47, 8995-8997. [CrossRef]

35. Russo, L.; Battocchio, C.; Secchi, V.; Magnano, E.; Nappini, S.; Taraballi, F.; Gabrielli, L.; Comelli, F.; Papagni, A.; Costa, B.; et al. Thiol-Ene Mediated Neoglycosylation of Collagen Patches: A Preliminary Study. Langmuir 2014, 30, 1336-1342. [CrossRef] [PubMed]

36. Agten, S.M.; Dawson, P.E.; Hackeng, T.M. Oxime Conjugation in Protein Chemistry: From Carbonyl Incorporation to Nucleophilic Catalysis. J. Pept. Sci. 2016, 22, 271-279. [CrossRef]

37. Kölmel, D.K.; Kool, E.T. Oximes and Hydrazones in Bioconjugation: Mechanism and Catalysis. Chem. Rev. 2017, 117, 10358-10376. [CrossRef]

38. van Vught, R.; Pieters, R.J.; Breukink, E. Site-specific functionalization of proteins and their applications to therapeutic antibodies. Comput. Struct. Biotechnol. J. 2014, 9, e201402001. [CrossRef]

39. Arranz-Gibert, P.; Patel, J.R.; Isaacs, F.J. The Role of Orthogonality in Genetic Code Expansion. Life 2019, 9, 58. [CrossRef]

40. Occhetta, P.; Visone, R.; Russo, L.; Cipolla, L.; Moretti, M.; Rasponi, M. VA-086 Methacrylate Gelatine Photopolymerizable Hydrogels: A Parametric Study for Highly Biocompatible 3D Cell Embedding. J. Biomed. Mater. Res. 2014, 103, 2109-2117. [CrossRef] 
41. Russo, L.; Sgambato, A.; Visone, R.; Occhetta, P.; Moretti, M.; Rasponi, M.; Nicotra, F.; Cipolla, L. Gelatin Hydrogels via Thiol-Ene Chemistry. Monatsh. Chem. 2015, 147, 587-592. [CrossRef]

42. García-Astrain, C.; Gandini, A.; Peña, C.; Algar, I.; Eceiza, A.; Corcuera, M.; Gabilondo, N. Diels-Alder "Click" Chemistry for the Cross-Linking of Furfuryl-Gelatin-Polyetheramine Hydrogels. RSC Adv. 2014, 4, 35578. [CrossRef]

43. Tamura, M.; Yanagawa, F.; Sugiura, S.; Takagi, T.; Sumaru, K.; Kanamori, T. Click-Crosslinkable and Photodegradable Gelatin Hydrogels for Cytocompatible Optical Cell Manipulation in Natural Environment. Sci. Rep. 2015, 5, 15060. [CrossRef] [PubMed]

44. Piluso, S.; Vukićević, R.; Nöchel, U.; Braune, S.; Lendlein, A.; Neffe, A.T. Sequential Alkyne-Azide Cycloadditions for Functionalized Gelatin Hydrogel Formation. Eur. Polym. J. 2018, 100, 77-85. [CrossRef]

45. Inoue, M.; Sasaki, M.; Nakasu, A.; Takayanagi, M.; Taguchi, T. An Antithrombogenic Citric Acid-Crosslinked Gelatin with Endothelialization Activity. Adv. Healthc. Mater. 2012, 1, 573-581. [CrossRef] [PubMed]

46. Bigi, A.; Cojazzi, G.; Panzavolta, S.; Roveri, N.; Rubini, K. Stabilization of Gelatin Films by Crosslinking with Genipin. Biomaterials 2002, 23, 4827-4832. [CrossRef]

47. Ko, C.-H.; Shie, M.-Y.; Lin, J.-H.; Chen, Y.-W.; Yao, C.-H.; Chen, Y.-S. Biodegradable Bisvinyl Sulfonemethyl-Crosslinked Gelatin Conduit Promotes Regeneration after Peripheral Nerve Injury in Adult Rats. Sci. Rep. 2017, 7, 17489. [CrossRef] [PubMed]

48. Guizzardi, R.; Vaghi, L.; Marelli, M.; Natalello, A.; Andreosso, I.; Papagni, A.; Cipolla, L. Gelatin-Based Hydrogels through Homobifunctional Triazolinediones Targeting Tyrosine Residues. Molecules 2019, 24, 589. [CrossRef]

49. Bigi, A.; Cojazzi, G.; Panzavolta, S.; Rubini, K.; Roveri, N. Mechanical and Thermal Properties of Gelatin Films at Different Degrees of Glutaraldehyde Crosslinking. Biomaterials 2001, 22, 763-768. [CrossRef]

50. Gough, J.E.; Scotchford, C.A.; Downes, S. Cytotoxicity of Glutaraldehyde Crosslinked Collagen/Poly(Vinyl Alcohol) Films Is by the Mechanism of Apoptosis. J. Biomed. Mater. Res. 2002, 61, 121-130. [CrossRef]

51. Li, Z.; Qian, L.; Li, L.; Bernhammer, J.C.; Huynh, H.V.; Lee, J.-S.; Yao, S.Q. Tetrazole Photoclick Chemistry: Reinvestigating Its Suitability as a Bioorthogonal Reaction and Potential Applications. Angew. Chem. Int. Ed. 2015, 55, 2002-2006. [CrossRef]

52. Zhao, S.; Dai, J.; Hu, M.; Liu, C.; Meng, R.; Liu, X.; Wang, C.; Luo, T. Photo-Induced Coupling Reactions of Tetrazoles with Carboxylic Acids in Aqueous Solution: Application in Protein Labelling. Chem. Commun. 2016, 52, 4702-4705. [CrossRef] [PubMed]

53. Siti, W.; Khan, A.K.; de Hoog, H.-P.M.; Liedberg, B.; Nallani, M. Photo-Induced Conjugation of Tetrazoles to Modified and Native Proteins. Org. Biomol. Chem. 2015, 13, 3202-3206. [CrossRef]

54. Huisgen, R.; Sauer, J.; Seidel, M. Ringöffnungen der Azole, VI. Die Thermolyse 2.5-disubstituierter Tetrazole zu Nitriliminen. Chem. Ber. 1961, 94, 2503-2509. [CrossRef]

55. Meier, H.; Heimgartner, H. Intramolekulare 1,3-dipolare Cycloadditionen von Diarylnitriliminen aus 2,5-Diaryltetrazolen. Helv. Chim. Acta 1985, 68, 1283-1300. [CrossRef]

56. Zhang, Y.; Liu, W.; Zhao, Z. Nucleophilic Trapping Nitrilimine Generated by Photolysis of Diaryltetrazole in Aqueous Phase. Molecules 2013, 19, 306-315. [CrossRef]

57. Vaghi, L.; Gaudino, E.; Cravotto, G.; Palmisano, G.; Penoni, A. A Structurally Diverse Heterocyclic Library by Decoration of Oxcarbazepine Scaffold. Molecules 2013, 18, 13705-13722. [CrossRef] [PubMed]

58. Tibiletti, F.; Penoni, A.; Palmisano, G.; Maspero, A.; Nicholas, K.; Vaghi, L. (1H-Benzo[d][1,2,3]Triazol-1-Yl)(5-Bromo-1-Hydroxy1H-Indol-3-Yl)Methanone. Molbank 2014, 2014, M829. [CrossRef]

59. Vaghi, L.; Coletta, M.; Coghi, P.; Andreosso, I.; Beverina, L.; Ruffo, R.; Papagni, A. Fluorine Substituted Non-Symmetric Phenazines: A New Synthetic Protocol from Polyfluorinated Azobenzenes. Arkivoc 2019, 2019, 340-351. [CrossRef]

60. Yousif, D.; Monti, M.; Papagni, A.; Vaghi, L. Synthesis of Phenazines from Ortho-Bromo Azo Compounds via Sequential Buchwald-Hartwig Amination under Micellar Conditions and Acid Promoted Cyclization. Tetrahedron Lett. 2020, 61, 152511. [CrossRef]

61. Stille, J.K.; Gotter, L.D. Polymers from 1,3-Dipole Addition Reactions. The Nitrilimine Dipole from Tetrazoles. J. Polym. Sci. A-1 Polym. Chem. 1969, 7, 2493-2504. [CrossRef]

62. Li, Y.; Zhang, W.; Sun, Z.; Sun, T.; Xie, Z.; Huang, Y.; Jing, X. Light-Induced Synthesis of Cross-Linked Polymers and Their Application in Explosive Detection. Eur. Polym. J. 2015, 63, 149-155. [CrossRef]

63. Ito, S.; Tanaka, Y.; Kakehi, A.; Kondo, K. A Facile Synthesis of 2,5-Disubstituted Tetrazoles by the Reaction of Phenylsulfonylhydrazones with Arenediazonium Salts. BCSJ 1976, 49, 1920-1923. [CrossRef]

64. Demko, Z.P.; Sharpless, K.B. Preparation of 5-Substituted 1H-Tetrazoles from Nitriles in Water. J. Org. Chem. 2001, 66, 7945-7950. [CrossRef] [PubMed]

65. Eastoe, J.E. The Amino Acid Composition of Mammalian Collagen and Gelatin. Biochem. J. 1955, 61, 589-600. [CrossRef]

66. Jariashvili, K.; Madhan, B.; Brodsky, B.; Kuchava, A.; Namicheishvili, L.; Metreveli, N. UV Damage of Collagen: Insights from Model Collagen Peptides. Biopolymers 2011, 97, 189-198. [CrossRef] [PubMed]

67. Nedunchezhian, N.; Kulandaivelu, G. Evidence for the Ultraviolet-B (280-320 Nm) Radiation Induced Structural Reorganization and Damage of Photosystem II Polypeptides in Isolated Chloroplasts. Physiol. Plant 1991, 81, 558-562. [CrossRef]

68. Monboisse, J.C.; Borel, J.P. Oxidative Damage to Collagen. In Free Radicals and Aging; Emerit, I., Chance, B., Eds.; Birkhäuser: Basel, Switzerland, 1992; pp. 323-327.

69. McMurray, T.A.; Byrne, J.A.; Dunlop, P.S.M.; McAdams, E.T. Photocatalytic and Electrochemically Assisted Photocatalytic Oxidation of Formic Acid on $\mathrm{TiO}_{2}$ Films under UVA and UVB Irradiation. J. Appl. Electrochem. 2005, 35, 723-731. [CrossRef] 
70. Xu, M.; Wei, L.; Xiao, Y.; Bi, H.; Yang, H.; Du, Y. Physicochemical and Functional Properties of Gelatin Extracted from Yak Skin. Int. J. Biol. Macromol. 2017, 95, 1246-1253. [CrossRef] [PubMed]

71. Rodin, V.V.; Izmailova, V.N. NMR Method in the Study of the Interfacial Adsorption Layer of Gelatin. Colloids Surf. A Physicochem. Eng. Asp. 1996, 106, 95-102. [CrossRef] 